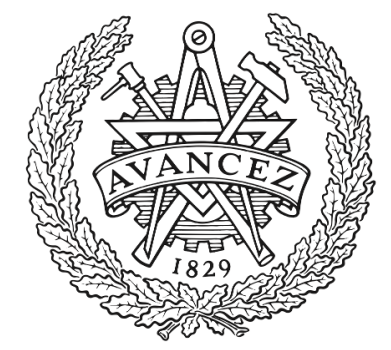

CHALMERS

UNIVERSITY OF TECHNOLOGY

\title{
A Robust and Biocompatible Bismuth Ellagate MOF Synthesized Under Green Ambient Conditions
}

Downloaded from: https://research.chalmers.se, 2023-04-26 11:35 UTC

Citation for the original published paper (version of record):

Grape, E., Flores, J., Hidalgo, T. et al (2020). A Robust and Biocompatible Bismuth Ellagate MOF Synthesized Under Green Ambient Conditions. Journal of the American Chemical Society, 142(39): 16795-16804. http://dx.doi.org/10.1021/jacs.0c07525

N.B. When citing this work, cite the original published paper. 


\section{A Robust and Biocompatible Bismuth Ellagate MOF Synthesized Under Green Ambient Conditions}

Erik Svensson Grape, J. Gabriel Flores, Tania Hidalgo, Eva Martínez-Ahumada, Aída Gutiérrez-Alejandre, Audrey Hautier, Daryl R. Williams, Michael O’Keeffe, Lars Öhrström, Tom Willhammar, Patricia Horcajada,* Ilich A. Ibarra,* and A. Ken Inge*

Cite This: J. Am. Chem. Soc. 2020, 142, 16795-16804

Read Online

ACCESS | Lill Metrics \& More | 回 Article Recommendations ｜（s Supporting Information

ABSTRACT: The first bioinspired microporous metal-organic framework (MOF) synthesized using ellagic acid, a common natural antioxidant and polyphenol building unit, is presented. $\mathrm{Bi}_{2} \mathrm{O}\left(\mathrm{H}_{2} \mathrm{O}\right)_{2}\left(\mathrm{C}_{14} \mathrm{H}_{2} \mathrm{O}_{8}\right) \cdot n \mathrm{H}_{2} \mathrm{O}$ (SU-101) was inspired by bismuth phenolate metallodrugs, and could be synthesized entirely from nonhazardous or edible reagents under ambient aqueous conditions, enabling simple scale-up. Reagent-grade and affordable dietary supplement-grade ellagic acid was sourced from tree bark and pomegranate hulls, respectively. Biocompatibility and colloidal stability were confirmed by in vitro assays. The material exhibits remarkable chemical stability for a bioinspired MOF $(\mathrm{pH}=2-14$, hydrothermal conditions, heated organic solvents, biological media, $\mathrm{SO}_{2}$ and $\mathrm{H}_{2} \mathrm{~S}$ ), attributed to the strongly chelating phenolates. A total $\mathrm{H}_{2} \mathrm{~S}$ uptake of $15.95 \mathrm{mmol} \mathrm{\textrm {g } ^ { - 1 }}$ was recorded, representing one of the highest $\mathrm{H}_{2} \mathrm{~S}$ capacities for a $\mathrm{MOF}$, where

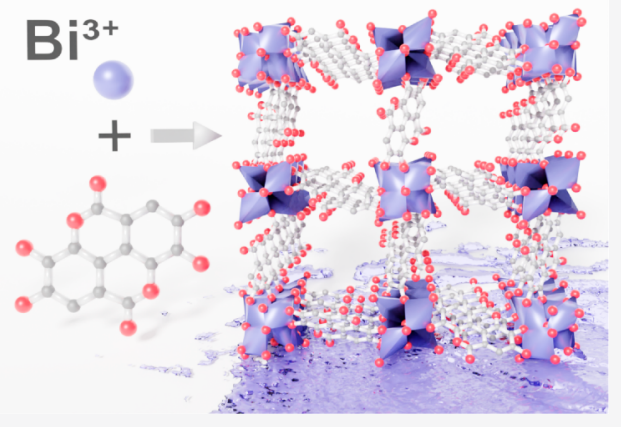
polysulfides are formed inside the pores of the material. Phenolic phytochemicals remain largely unexplored as linkers for MOF synthesis, opening new avenues to design stable, eco-friendly, scalable, and low-cost MOFs for diverse applications, including drug delivery.

\section{INTRODUCTION}

Tannins are natural polyphenols which can be found in a substantial part of the plant kingdom and are the second most abundant source of natural aromatic molecules after lignin. ${ }^{1}$ They have traditionally been used for tanning leather, yet show great promise as a rich supply of precursors for green chemistry. Considering the general structure of tannin derivatives, having multiple aromatic rings with phenol functionalities, they stand out as a renewable source of rigid molecules. ${ }^{1,2}$

Rigid organic molecules capable of bridging metal cations are a principal component in the crystal chemistry of metalorganic frameworks (MOFs) - a class of porous hybrid materials which has shown an immense growth of compositions and topologies for over two decades, the main allure being the possibility of designing framework materials through a direct assembly of selected building units. ${ }^{3,4}$ Considering the great variety of MOFs, the number of structures bridged only through phenolate ligands are few (representing $<0.0008 \%$ of MOF reports), and existing examples involve synthetic linkers such as tetrahydroxybenzoate, ${ }^{5}$ dihydroxybenzoquinone, ${ }^{6-8}$ and hexahydroxytriphenylate ligands. ${ }^{9-11}$ Numerous phenolate-based MOFs have been associated with higher chemical stability (especially in aqueous media) than carboxylate based MOFs - a consequence of the higher $\mathrm{pK}_{\mathrm{a}}$ of the phenolate groups, leading to strong chelation. ${ }^{12,13}$

Inspired by the potential stability of phenolate-based MOFs, together with the growing global demand to broaden the use of renewable resources, we have turned to tannins for the synthesis of green MOFs-specifically, gallotannins and ellagitannins, which contain gallic acid or ellagic acid subunits, respectively. While gallic acid, which consists of both carboxylic acid and phenol functional groups, has been utilized as a linker for the synthesis of a handful of MOFs, ${ }^{14-19}$ surprisingly ellagic acid (Figure 1) has seemingly never been used for MOF synthesis. Currently, the only entry in the Cambridge Structural Database (CSD) containing an ellagate anion together with a metal cation is a metal complex composed of two ruthenium cations linked by ellagate and capped by acetylacetonate. ${ }^{20}$ Additionally, iron, manganese, and zinc ellagate materials have been developed for applications in phototherapy or as templates for porous

Received: July 13, 2020

Published: September 7, 2020 
<smiles>O=c1oc2c(O)c(O)cc3c(=O)oc4c(O)c(O)cc1c4c23</smiles>

Figure 1. Ellagic acid-the phenolic building unit of ellagitannins.

carbons, yet no crystal structures nor porosities were reported. $^{21,22}$

Naturally high contents of ellagic acid are found in foods such as strawberries, raspberries, grapes, walnuts, pecans, and pomegranates, as well as in beverages such as wine, whiskey, and other spirits. ${ }^{23-25}$ While the general benefit of consuming antioxidants, such as ellagic acid, remains up for debate due to challenges in maintaining oxidation homeostasis in healthy individuals, ${ }^{26,27}$ their protective properties in oxidation-related chronic diseases, as well as their antimicrobial, antiviral, antiinflammatory, and anticancer activities have been established. $^{28,29}$ In light of the scarcity with which phenolic bioderived molecules have been utilized for MOF synthesis, we find ellagic acid to be an appealing yet previously unexplored linker for the synthesis of bioinspired MOFs (BioMOFs) since (1) it is edible, biocompatible, bioactive, and has been consumed throughout human history (recommended intake $\sim 5 \mathrm{mg} \mathrm{day}^{-1}$ in adults, ${ }^{30}$ reaching half-maximal inhibitory concentration $\left(\mathrm{IC}_{50}\right)$ values of $23.5 \mu \mathrm{g} \mathrm{mL} \mathrm{g}^{-1}$ in diverse tumor cell lines or when administrating $\sim 60 \mathrm{mg} \mathrm{kg}^{-1}$ body weight for preclinical doses); (2) it is extracted from plant-based materials often considered as waste, such as tree bark and fruit peels; (3) can act as a rigid spacer between cations, contributing to the porosity of the resulting framework; (4) it has a centrosymmetric molecular structure, increasing the likelihood of it taking the role as a bridging linker; (5) it can chelate to metal cations, giving rise to strong five-membered rings; and (6) it has a low production cost.

Other polycomplexant biomolecules have previously been proposed as good candidates for the synthesis of BioMOFs, ${ }^{31,32}$ and the resulting materials could potentially serve as delivery vehicles for active pharmaceutical ingredients (APIs) or as imaging agents. ${ }^{33}$ However, many of the previously described BioMOFs are synthesized also using auxiliary nonbiological linker molecules and/or hazardous organic solvents. Despite the large appeal of using bioderived molecules for the synthesis of MOFs, examples are few and chemical stability is seldom thoroughly demonstrated, nor is biocompatibility. ${ }^{34-38}$ To the best of our knowledge, only two microporous BioMOFs have been synthesized in water without auxiliary ligands: a magnesium gallate and an aluminum fumarate. ${ }^{17,39}$ However, these MOFs demonstrate poor overall chemical stability, particularly in aqueous solutions.

In order to develop stable and biocompatible BioMOFs, the choice of metal cation is equally important. One nontoxic metal cation which has established biomedical applications is $\mathrm{Bi}^{3+35,40,41}$ As the second heaviest member of group 15 in the periodic table, bismuth is surrounded by notoriously toxic elements, yet bismuth itself has been found to have very low toxicity. With median lethal doses $\left(\mathrm{LD}_{50}\right)$ of about $5 \mathrm{~g} \mathrm{~kg}^{-1}$ in rat models, the toxicity of bismuth and many of its compounds are comparable to or less than that of sodium chloride. ${ }^{42}$ Furthermore, bismuth compounds have a two-century-long track record as APIs due to their inherent bioactivity and antimicrobial properties. ${ }^{43}$ Bismuth subsalicylate (PeptoBismol) and bismuth subgallate are APIs made with the ligands salicylic acid and gallic acid, respectively. ${ }^{44}$ Similar to ellagic acid, these are naturally occurring therapeutic phenolic molecules, making ellagic acid an appropriate choice of ligand to combine with $\mathrm{Bi}^{3+}$ for the development of a potentially biocompatible and bioactive MOF. So far, the use of bismuth in the synthesis of MOFs has been fairly limited, with only seven $\mathrm{Bi}(\mathrm{III})-\mathrm{MOF}$ s that have been reported to demonstrate porosity to nitrogen. ${ }^{40,41,45-49}$ As all seven are exclusively based on synthetic carboxylate ligands, this begs the question, what new MOF structures can be acquired using $\mathrm{Bi}^{3+}$ and phenol-based linkers such as ellagic acid? The resulting material could potentially combine the biocompatible and bioactive features of both the metal cation and the organic linker, and would ideally be synthesized using green aqueous conditions.

In short, we report the synthesis, crystal structure, and physicochemical properties of a biocompatible and microporous bismuth ellagate framework (denoted SU-101) - the first MOF based on the bioactive phytochemical ellagic acid. For a bioinspired MOF, the material exhibits remarkable chemical stability and thermal stability under vacuum and in nitrogen, which led to investigations on its use as an adsorbent of the highly acidic gases $\mathrm{SO}_{2}$ and $\mathrm{H}_{2} \mathrm{~S}$, both of which are wellknown air-pollutants associated with severe environmental and health issues. ${ }^{50,51}$ Additionally, the environmentally friendly synthesis procedure, using a plant-derived linker molecule in water under ambient conditions, facilitates an easy scale-up process.

\section{RESULTS AND DISCUSSION}

Synthesis of SU-101. Bismuth ellagate (SU-101) was prepared from an aqueous suspension of bismuth acetate and ellagic acid stirred under ambient conditions (i.e., room temperature and atmospheric pressure in air) for $48 \mathrm{~h}$. Phase purity and synthesis reproducibility were improved through the introduction of acetic acid as a modulator ( $6 \%$ by volume, from either glacial acetic acid or a distilled white vinegar stock solution, $\mathrm{pH} \approx 2.3$; see the Supporting Information, SI, for details). Such a concentration of acetic acid is well within the range of what is found in common household vinegar (5-12 vol \% of acetic acid in distilled white vinegar)..$^{52}$

Two different sources of ellagic acid were utilized for the synthesis of SU-101: (1) 97\% chemical reagent-grade ellagic acid isolated from chestnut tree bark and (2) inexpensive $90 \%$ dietary supplement-grade ellagic isolated from pomegranate hulls, marketed as an edible antioxidant. Both starting materials resulted in high quality and phase-pure SU-101 based on powder X-ray diffraction (PXRD) and sorption data (Figures 2 , S11, and S12). In both cases, the mixtures remained as suspensions throughout the reaction but nonetheless resulted in phase-pure SU-101. High percent yields of SU-101 were obtained at a small $30 \mathrm{~mL}$ reaction scale (76\% yield; $0.28 \mathrm{~g}$ ). Through a linear scale-up, a $600 \mathrm{~mL}$ large-scale synthesis resulted in a similar percent yield $(74 \%, 5.6 \mathrm{~g})$ of material in a single batch. Although the estimated space-time-yield using these conditions (approximately $5 \mathrm{~kg} \mathrm{~m}^{-3}$ day $^{-1}$ ) is lower than values obtained for highly scalable MOFs $\left(>1000 \mathrm{~kg} \mathrm{~m}^{-3}\right.$ day $\left.^{-1}\right),{ }^{38,53}$ one should note the simplicity and cost-efficiency of the synthesis procedure, carried out at atmospheric pressure without heating or using any other forms of external energy input. 


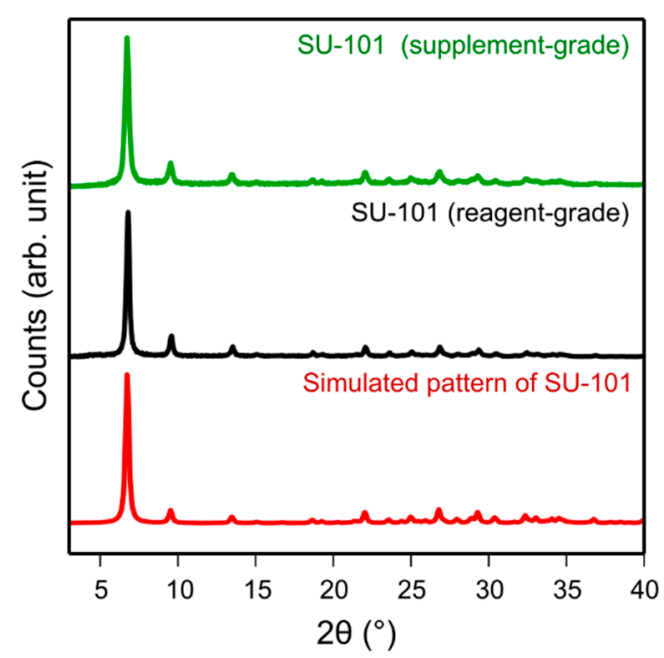

Figure 2. Powder X-ray diffraction patterns of SU-101 made from reagent-grade ellagic acid (97\% ellagic acid, isolated from chestnut tree bark) and supplement-grade ellagic acid (90\% ellagic acid, isolated from pomegranate hulls), as well as a simulated powder X-ray diffraction pattern of SU-101.

Structure of SU-101. Due to the small crystallite size, the structure of SU-101 could not be solved using single-crystal Xray diffraction (SCXRD). Instead, the crystal structure was determined using 3D electron diffraction (3DED), a method previously used to solve the structure of the microcrystalline metallodrug bismuth subgallate, as well as several $\mathrm{Bi}(\mathrm{III})$ MOFs. ${ }^{41,44,45}$ For structure determination, 3DED data were acquired from larger $3 \mu \mathrm{m}$ long bladed crystals (Figure 3,

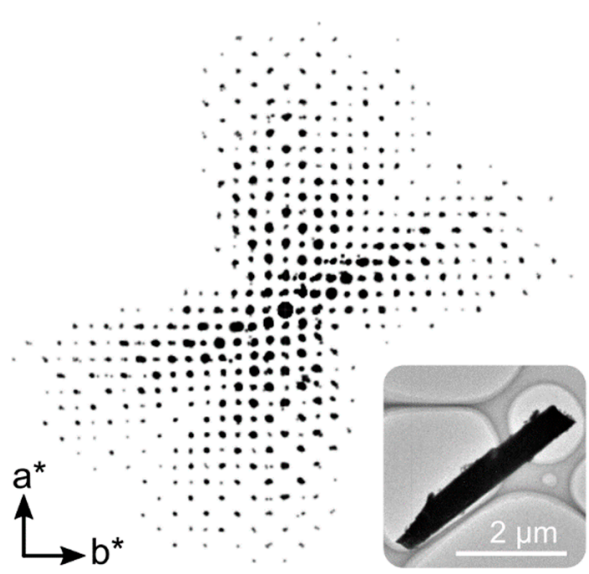

Figure 3. Reciprocal space projection of 3DED data collected on SU101 , viewed along $c^{*}$, and an image of the crystal studied (larger crystals were specifically prepared for structure determination using an alternative hydrothermal synthesis procedure).

Table S1) which were synthesized using an alternative synthesis method under hydrothermal conditions (see SI for details). The structure was solved from the collected 3DED data and further refined against high-resolution powder X-ray diffraction (HR-PXRD) data in the tetragonal space group $P 4_{2} / n(a=18.62 \AA, c=5.55 \AA)$.

The framework of SU-101 consists of rod-shaped inorganic building units (IBUs) which run parallel to the $c$-axis and are linked together by ellagate anions in the $a b$-plane (Figure $4 \mathrm{a}, \mathrm{c}$ ), forming one-dimensional pores roughly $6-7 \AA$ in diameter, taking into account the van der Waals radii of the framework atoms. The asymmetric unit of SU-101 contains half of an ellagate anion and one $\mathrm{Bi}^{3+}$ cation, as well as three individual oxygen atoms interpreted as (1) a coordinated water molecule, (2) a guest water molecule within the one-dimensional channels, and last, (3) a single $\mu_{4}$-oxygen, resulting in an overall charge neutral framework with the formula $\mathrm{Bi}_{2} \mathrm{O}$ $\left(\mathrm{H}_{2} \mathrm{O}\right)_{2}\left(\mathrm{C}_{14} \mathrm{H}_{2} \mathrm{O}_{8}\right) \cdot n \mathrm{H}_{2} \mathrm{O}(n=2$, Figure $\mathrm{S} 5)$. The coordination number of $\mathrm{Bi}^{3+}$ is six, of which three bonds form with coordinating phenolates, two $\mu_{4}$-oxygens, and a terminally coordinated water molecule (Figure $4 \mathrm{~b}$ ). The phenolate groups chelate to $\mathrm{Bi}^{3+}$ cations, and all four phenolate groups of the ellagate are presumed to be deprotonated based on the short $\mathrm{Bi}-\mathrm{O}$ bonds, between 2.1 and $2.3 \AA$. These short distances are indicative of strongly chelating phenolates as longer $\mathrm{Bi}-\mathrm{O}$ distances are found in the previously published $\mathrm{Bi}(\mathrm{III})$-carboxylate MOFs (typically in the range of $2.4-2.8 \AA$ ). On each end of the ellagate linker, one of the phenolates coordinates to a single $\mathrm{Bi}^{3+}$, while the other bridges two $\mathrm{Bi}^{3+}$ along the rod-shaped IBU (Figure 4d). The shortest intermolecular carbon-carbon distance between neighboring ellagates is $3.51 \AA$ indicating $\pi-\pi$ stacking between the ellagate linkers down the $c$-axis, further stabilizing the structure. The non-coordinated water molecules occupying the one-dimensional channels form hydrogen bonds to neighboring water molecules as well as the carbonyl oxygens of the lactone rings pointing into the channels, with oxygen-oxygen distances in the range of 2.7-2.9 $\AA$ (Figure S6).

To simplify the description of SU-101, and to classify the structure, a topological analysis was performed. The choice of nodes when deconstructing the rod-shaped inorganic building unit was carried out as described by O'Keeffe and Yaghi, ${ }^{54}$ where the point of extension of the linker, in this case, the midpoint between each pair of phenolates in the ellagate anions, ortho to one another, was selected as a node (Figure $4 \mathrm{~g}, \mathrm{~h})$. These nodes were then linked to neighboring vertices outlining the rod, resulting in a 6-c node, which, upon considering the linkage of rods by ellagate anions, gives the uninodal 7-coordinated net svd (Figure 4e,f).

Physicochemical Characterization. Thermogravimetric analysis (TGA) of SU-101 is in agreement with the proposed sum formula of $\mathrm{Bi}_{2} \mathrm{O}\left(\mathrm{H}_{2} \mathrm{O}\right)_{2}\left(\mathrm{C}_{14} \mathrm{H}_{2} \mathrm{O}_{8}\right) \cdot n \mathrm{H}_{2} \mathrm{O}(n=1$, Figure S7). The lower water content compared to that determined from HR-PXRD $(n=2)$ in a sealed capillary, and the immediate loss of water observed in the TGA data indicates that some of the water molecules in the pores are readily lost from the material at conditions close to room temperature.

The thermal stability of SU-101 was assessed by variable temperature powder X-ray diffraction (VT-PXRD), revealing that the framework remains crystalline under vacuum or in a nitrogen atmosphere at temperatures of up to $500{ }^{\circ} \mathrm{C}$ (Figures S8 and S9). While VT-PXRD tests are not always employed to study the thermal stability of MOFs, hindering an overall comparison, an intact and open framework at $500{ }^{\circ} \mathrm{C}$ (independent of atmosphere) has only been shown for a small handful of MOFs, such as CFA-2 and ZIF- $8 .{ }^{55}$ The framework remains intact up to $250{ }^{\circ} \mathrm{C}$ in air, after which the ellagate anion likely oxidizes, leading to a loss of crystallinity (Figure S10). This has also been observed with other MOFs composed of phenolate linkers and has been attributed to the relative ease with which phenolates are oxidized. ${ }^{12}$

The permanent microporosity of SU-101 was confirmed by $\mathrm{N}_{2}$ sorption experiments at $77 \mathrm{~K}$ after activating the material at $150{ }^{\circ} \mathrm{C}$ under vacuum for $10 \mathrm{~h}$. Type I $\mathrm{N}_{2}$ isotherms, typical 


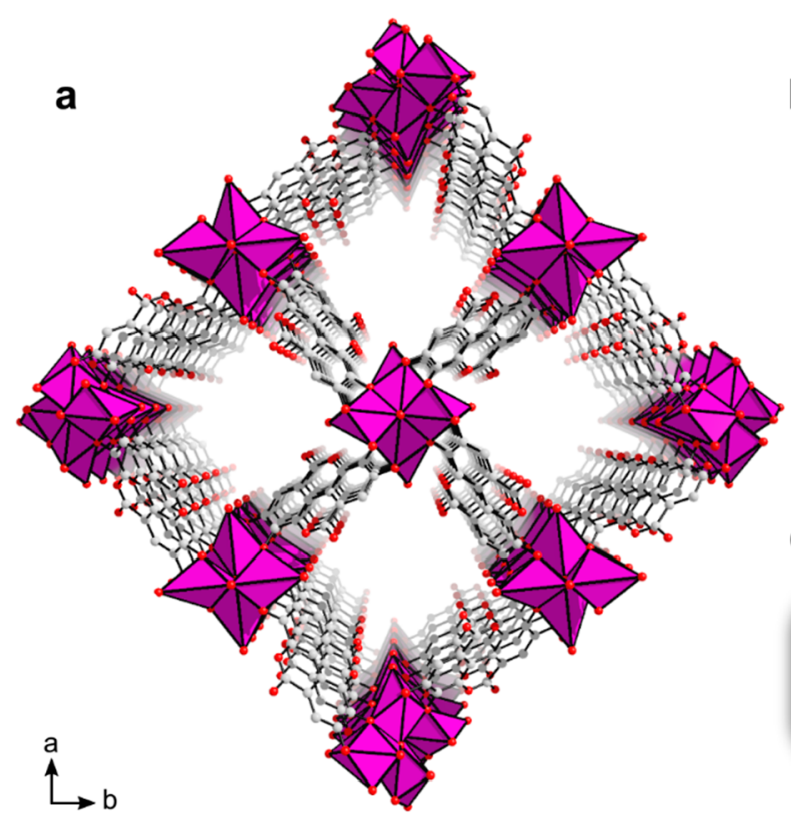

b
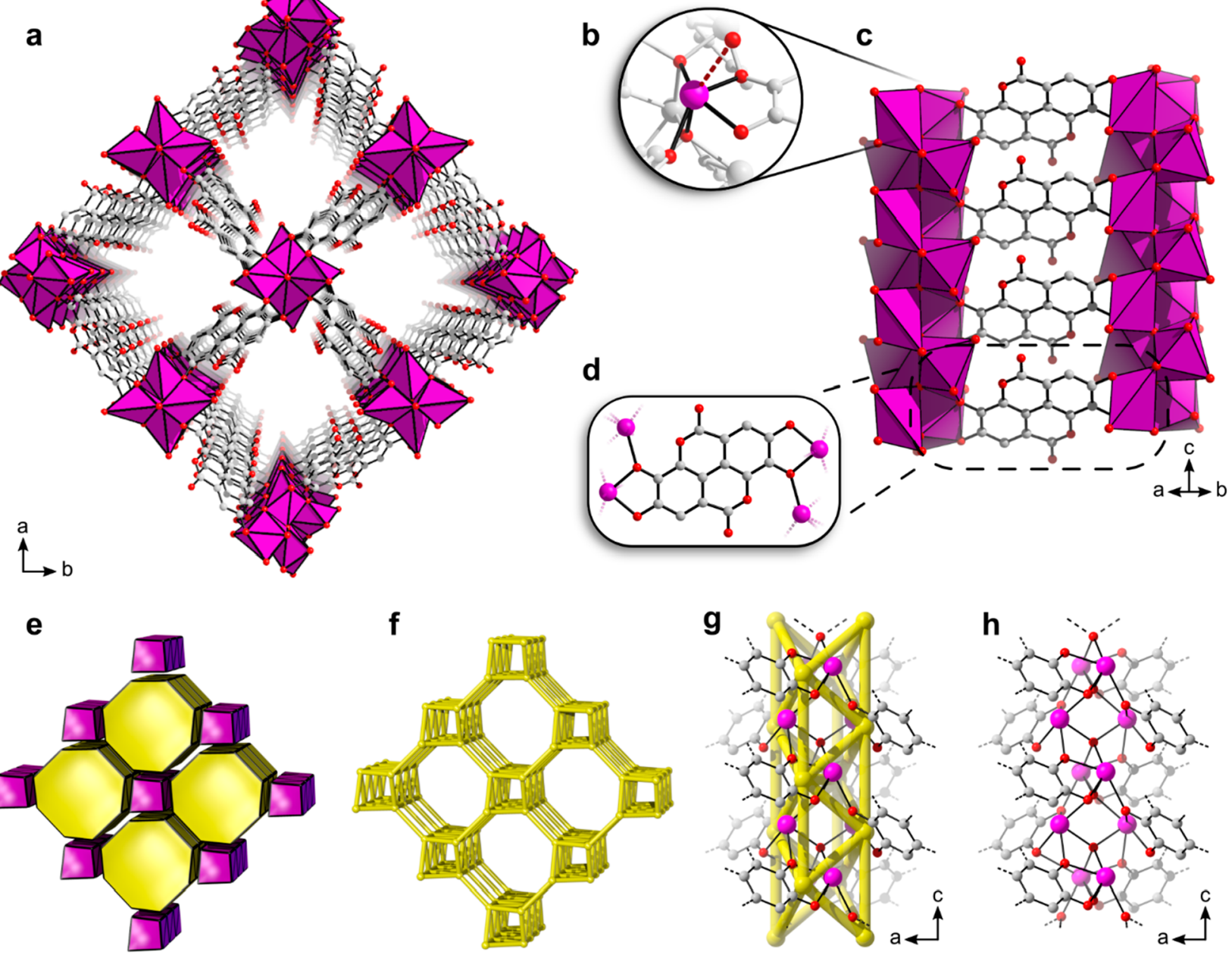

Figure 4. (a) The structure of SU-101 as viewed down the c-axis. Hydrogen atoms and water molecules in the pores are omitted for clarity. (b) The coordination environment around $\mathrm{Bi}^{3+}$. The bond to a coordinated water molecule is represented as a dashed line. (c, d) Chelation of ellagate toward the bismuth oxo rods. (e) The tiling of the svd net. (f) The underlying svd net. (g, h) Choice of nodes for the deconstruction of the infinite IBU.

for microporous materials, were observed (Figures S11 and $\mathrm{S} 12)$, with a Brunauer-Emmett-Teller surface area $\left(S_{\mathrm{BET}}\right)$ of $412 \mathrm{~m}^{2} \mathrm{~g}^{-1}$ when using reagent-grade ellagic acid for synthesis and $350 \mathrm{~m}^{2} \mathrm{~g}^{-1}$ for a washed large-scale batch produced from supplement-grade ellagic acid. These values are within the range of surface areas previously reported for $\mathrm{Bi}(\mathrm{III})-\mathrm{MOF}$ $\left(70-1100 \mathrm{~m}^{2} \mathrm{~g}^{-1}\right) .^{40,41,45-49}$

The average pore size of SU-101 was estimated to be approximately $6.8 \AA$ (Figure S13), in good agreement with the crystallographic model (6-7 $\AA$ ). The pore size distribution was calculated using the density functional theory (DFT) method with a $\mathrm{N}_{2}$ slit pore model. The trend toward lower surface areas obtained by $\mathrm{Bi}(\mathrm{III})$-MOFs in units of $\mathrm{m}^{2} \mathrm{~g}^{-1}$ is in part due to the heavy nature of $\mathrm{Bi}^{3+}$ compared to the significantly lighter metal cations found in the large majority of other MOFs. The adsorption of other environmentally and industrially relevant gases, $\mathrm{CO}_{2}$ and $\mathrm{CH}_{4}$, was also investigated (Figure S14), where SU-101 displays a higher affinity toward $\mathrm{CO}_{2}$ over $\mathrm{N}_{2}$ and $\mathrm{CH}_{4}$, due to the lower saturation pressure of $\mathrm{CO}_{2}$. The $\mathrm{CO}_{2} /$ $\mathrm{N}_{2}$ selectivity for a hypothetical flue gas mixture, containing 15 $\mathrm{kPa} \mathrm{CO}_{2}$ and $85 \mathrm{kPa} \mathrm{N}$ was estimated using the equation $s=$ $(\mathrm{q} 1 / q 2) /(p 1 / p 2)$, giving a $\mathrm{CO}_{2} / \mathrm{N}_{2}$ selectivity of $\sim 35$, yet other MOFs and porous materials have shown higher selectivity and $\mathrm{CO}_{2}$ uptakes under similar conditions. ${ }^{56}$ Even so, bismuth-based MOFs are of interest as precursors to electrocatalysts for $\mathrm{CO}_{2}$ reduction, as demonstrated using CAU-7. ${ }^{57}$

The chemical stability of SU-101 was investigated by mimicking different industrially relevant media (e.g., for catalysis). Hence, as to cover a large range of chemical properties, the selected solvents were acetone, acetonitrile, chlorobenzene, cyclohexane, dichloromethane, 1,4-dioxane, dimethylformamide, dimethyl sulfoxide, ethanol, ethyl acetate, methanol, $n$-pentane, pyrrolidine, tetrahydrofuran, and toluene. PXRD results indicated that the structure remains intact in all of these solvents at room temperature (Figure S15), as well as when heated to $80{ }^{\circ} \mathrm{C}$ for $24 \mathrm{~h}$ in these solvents, with the exception of toluene where additional peaks, consistent with partial degradation, were observed (Figure S16). The high chemical stability of SU-101 arises from the presence of the two deprotonated phenolate oxygen atoms, chelating strongly to the $\mathrm{Bi}^{3+}$. As described for MIL-163, ${ }^{12}$ the strong metallinker interaction leads to a material that is resistant to harsh chemical conditions.

An ongoing challenge for MOFs is their stability in various aqueous conditions. As such, the $\mathrm{pH}$-dependent stability of 
SU-101 was evaluated by exposing the material to aqueous solutions of $\mathrm{HCl}$ or $\mathrm{NaOH}$, showing that the framework remains intact over a large $\mathrm{pH}$-range, $2<\mathrm{pH} \leq 14$ (Figure S18). The structure of SU-101 also remained unchanged under hydrothermal conditions $\left(180{ }^{\circ} \mathrm{C}\right.$ for $24 \mathrm{~h}$; Figure S16). However, at highly acidic conditions $(\mathrm{pH} \leq 2)$, SU-101 is converted to $\mathrm{BiOCl}$ (Figure S18).

Immersion of SU-101 in potentially coordinative carboxylic acids (propionic acid, acetic acid and oxalic acid) was also investigated. The material remains intact at room temperature but decomposes at $80{ }^{\circ} \mathrm{C}$ in propionic acid. In acetic acid SU101 undergoes partial transformation at room temperature and full degradation at $80^{\circ} \mathrm{C}$. In a concentrated oxalic acid solution decomposition occurs at room temperature (Figures S15 and S16).

As the ability to withstand the presence of coordinative species is of great importance for both biological as well as industrial applications, SU-101 was exposed to simulated physiological conditions such as phosphate-buffered saline (PBS) solution and cell culture medium (RPMI) at $37{ }^{\circ} \mathrm{C}$. As seen in Figure 5, the material remains intact despite the

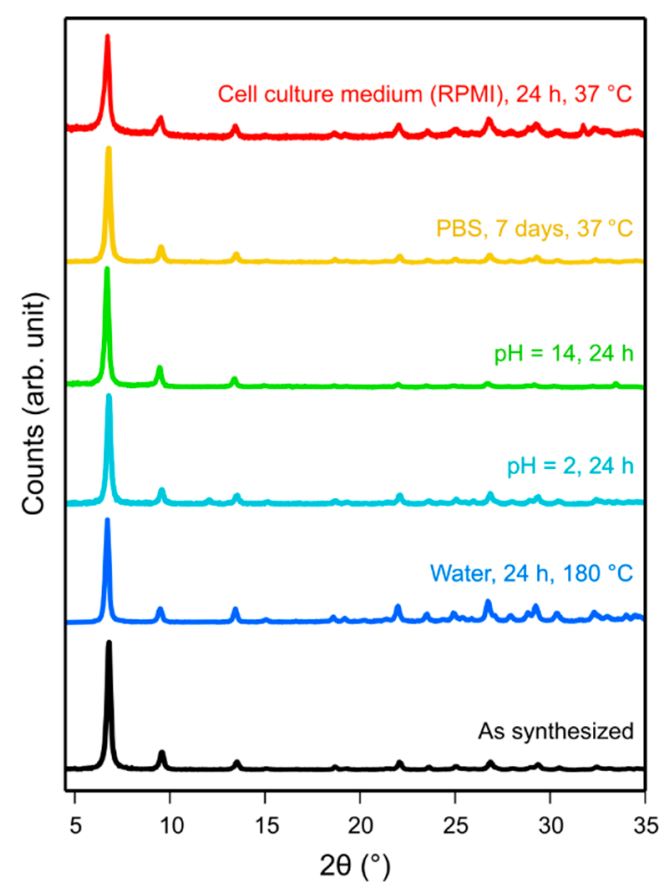

Figure 5. Powder X-ray diffraction patterns of SU-101 before and after exposure to a variety of aqueous conditions including a wide $\mathrm{pH}$ range, hydrothermal conditions and simulated biological media. The limit of stability in acidic solutions can be seen at $\mathrm{pH}=2$, where a small peak appears at $2 \theta=12^{\circ}$, attributed to the formation of $\mathrm{BiOCl}$.

presence of glucose, salts, vitamins, antibiotics, and amino acids, even for longer periods of time $(24 \mathrm{~h})$. Specifically, the stability of SU-101 was also evaluated in the presence of Lcysteine and L-cystine, showing that the material remains intact in solutions with these sulfur-containing biomolecules (Figure S17). Considering these results, the overall chemical stability of SU-101 appears to be better or similar to that of hallmark MOFs such as UiO-66 and ZIF-8, with the added value of using nontoxic reagents in a water-based synthesis. ${ }^{58}$

Colloidal Stability and Biocompatibility. In addition to the structural and chemical stability of a material in biorelevant conditions, insight into the physicochemical properties such as charge, surface chemistry, and colloidal stability will affect the affinity to different biological structures, which in turn governs the efficacy and biodistribution of the material. ${ }^{59-61}$ Aqueous suspensions of SU-101 exhibit a small and monodisperse particle size of $129 \pm 2 \mathrm{~nm}(\mathrm{PdI} \sim 0.3)$, a size which is a priori compatible with intravenous drug administration. ${ }^{62}$ This hydrodynamic diameter, obtained by dynamic light scattering (DLS) measurements, assumes a spherical particle shape in solution, yet is in fair agreement with the microscopic observations acquired by TEM (Figures S1 and S2), showing polydispersed elongated crystals at its dry state $(176 \pm 88 \mathrm{~nm}$ length and $51 \pm 18 \mathrm{~nm}$ wide; measured from 200 particles). This slight particle size difference between methods has been previously observed. $^{62}$ In addition, previous intravenous toxicological studies using elongated MOF nanoparticles did not show any signs of in vivo toxicity associated with the MOF morphology. ${ }^{62,63}$ As such, a biocompatible character of SU-101 is expected (see below). When monitoring the particle size over time $(24 \mathrm{~h}), \mathrm{SU}-101$ exhibited suitable colloidal stability in water (average size $\sim 137 \pm 4 \mathrm{~nm}$; Figure S19) with a strongly negative $\zeta$-potential $(-35 \mathrm{mV})$, possibly due to the presence of partially coordinated ellagate anions or hydroxyl groups completing the coordination sphere of superficial $\mathrm{Bi}^{3+}$. In turn, the resulting electrostatic repulsions might be responsible for the observed colloidal stability. In RPMI, the observed particle size is slightly larger than that in water (180 $\pm 26 \mathrm{~nm})$, while also showing a less negative $\zeta$-potential $(-10$ $\mathrm{mV})$. This is expected as proteins in the RPMI media (supplemented with FBS) can adhere to the particle surfaces, hampering direct interparticle contact through the formation of a protein corona, leading to lower surface charge values (from $-35 \pm 1$ to $-10 \pm 0 \mathrm{mV}$ ), in agreement with previous colloidal MOF behaviors. ${ }^{62,64}$ Colloidal stability is maintained over time, with a particle size of $200 \pm 11 \mathrm{~nm}$ over $24 \mathrm{~h}$, further indicating properties suitable for biological applications.

To explore the intrinsic qualities and potential applications of this green material, in vitro cytotoxicity tests were performed to assess the biocompatibility of SU-101. For these purposes, a promyelocytic cell line (HL-60) was selected as a model for differentiated phagocytic cells and granulocytes involved in the body's defense. Remarkably, after $24 \mathrm{~h}$ of cell contact, a very low cytotoxicity profile was observed $(80 \%$ maximum inhibitory concentration, $\left.\mathrm{IC}_{80}=1000 \mu \mathrm{gmL}^{-1}\right)$, even when exposed to very high concentrations of SU-101 (up to $1200 \mu \mathrm{gmL}^{-1}$; Figure S20). This is in agreement with the absence of severe toxicity observed for the individual reagents-ellagic acid and bismuth acetate. Therefore, SU101 seems to be a promising candidate for environmental and biological applications, such as depollution and drug delivery, both being chemically stable and biocompatible.

$\mathrm{SO}_{2}$ and $\mathrm{H}_{2} \mathrm{~S}$ Capture in SU-101. Due to the remarkable chemical stability demonstrated by SU-101, adsorption of the acidic gases $\mathrm{SO}_{2}$ and $\mathrm{H}_{2} \mathrm{~S}$ was investigated. Sulfur dioxide $\left(\mathrm{SO}_{2}\right)$ is a toxic gas which was classified by the World Health Organization as one of the most hazardous air pollutants, associated with increased respiratory problems ${ }^{50,65}$ and mortality. ${ }^{66}$ Similarly, hydrogen sulfide $\left(\mathrm{H}_{2} \mathrm{~S}\right)$ is a highly toxic chemical and exposure to concentrations of over 100 ppm can be fatal as it is rapidly absorbed into the bloodstream, limiting $\mathrm{O}_{2}$ uptake at a cellular level. ${ }^{51,67,68}$ However, few MOFs have demonstrated stability upon exposure to either $\mathrm{SO}_{2}$ or $\mathrm{H}_{2} \mathrm{~S}$, principally due to the formation of strong and irreversible metal-sulfur bonds. ${ }^{69-76}$ 
To investigate the adsorptive properties of SU-101, $\mathrm{SO}_{2}$ sorption isotherms were acquired at pressures between 0 to 1 bar at $298 \mathrm{~K}$ on an activated sample using a Dynamic Gravimetric Gas/Vapor Sorption Analyzer, DVS vacuum (see $\mathrm{SI}$ ). The resulting $\mathrm{SO}_{2}$ isotherm shows a total uptake of 2.2 $\mathrm{mmol} \mathrm{g}^{-1}$ (Figure S21). Although this value is considerably lower than the uptake of other MOFs, ${ }^{70,72,77,78}$ the stability of SU-101 upon adsorption-desorption cycling was investigated and structural integrity after both dry and humid $\mathrm{SO}_{2}$ sorption was confirmed by PXRD (Figures S25 and S27). Furthermore, the host-guest interaction between $\mathrm{SU}-101$ and $\mathrm{SO}_{2}$ was quantified, evaluating the isosteric heat of adsorption $(\Delta H)$ for $\mathrm{SO}_{2}$ at low coverage for SU-101 (estimated by fitting two adsorption isotherms at 303 and $308 \mathrm{~K}$ to a ClausiusClapeyron equation, Figures S22 and S23). The low isosteric heat of adsorption for $\mathrm{SO}_{2}\left(\Delta H=-29.6 \mathrm{~kJ} \mathrm{~mol}^{-1}\right)$ indicates that no $\mathrm{M}-\mathrm{SO}_{2}$ interactions occur $\left(>90 \mathrm{~kJ} \mathrm{~mol}^{-1}\right) .{ }^{79}$ Since the heat of adsorption was low, cycling experiments were carried out, where activation of SU-101 between cycles was achieved by applying vacuum $\left(1.7 \times 10^{-6}\right.$ Torr $)$ for only $15 \mathrm{~min}$ at 298 $\mathrm{K}$. Using this procedure, it was demonstrated that the $\mathrm{SO}_{2}$ capture capacity $(1 \mathrm{bar}, 298 \mathrm{~K})$ remains constant during 50 adsorption-desorption cycles $\left(2.200 \pm 0.004 \mathrm{mmol} \mathrm{g}^{-1}\right.$, Figure S24) with the structure remaining intact (Figure S25).

$\mathrm{H}_{2} \mathrm{~S}$ capture by SU-101 was investigated with a series of breakthrough experiments ( $4.3 \mathrm{vol} \% \mathrm{H}_{2} \mathrm{~S}$ with 95.7 vol \% of $\mathrm{N}_{2}$ ). Samples were first activated at $120{ }^{\circ} \mathrm{C}$ for $6 \mathrm{~h}$ under a flow of dry $\mathrm{N}_{2}$ gas, after which the material was cooled down to 25 ${ }^{\circ} \mathrm{C}$. The resultant breakthrough $\mathrm{H}_{2} \mathrm{~S}$ experiment led to a gas uptake of $15.95 \mathrm{mmol} \mathrm{g}^{-1}$, i.e., $542 \mathrm{mg} \mathrm{g}^{-1}$, (Figures 6 and

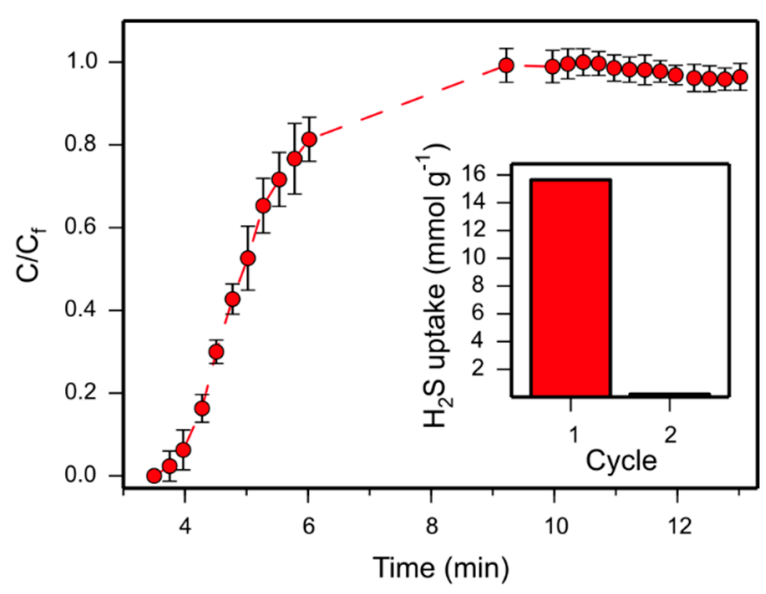

Figure 6. Breakthrough curve of $\mathrm{H}_{2} \mathrm{~S}$ adsorption by SU-101 at $25{ }^{\circ} \mathrm{C}$ and 1 bar. The inset shows the comparative $\mathrm{H}_{2} \mathrm{~S}$ adsorption capacities for each cycle.

S28) equivalent to $515 \mathrm{~cm}^{3} \mathrm{~g}^{-1}$. Surprisingly, considering that the $S_{\text {BET }}$ of SU-101 is $412 \mathrm{~m}^{2} \mathrm{~g}^{-1}$, this $\mathrm{H}_{2} \mathrm{~S}$ uptake is one of the highest reported, and is comparable to the top-performing MOFs, such as Ni-CPO-27 (12.0 mmol g ${ }^{-1}, S_{\text {BET }}=1545 \mathrm{~m}^{2}$ $\left.\mathrm{g}^{-1}\right){ }^{80}$ MFM-300(Sc) $\left(16.5 \mathrm{mmolg}^{-1}, S_{\mathrm{BET}}=1360 \mathrm{~m}^{2} \mathrm{~g}^{-1}\right)^{81}$ or MIL-53(Al)-TDC $\left(18.1 \mathrm{mmol} \mathrm{g}^{-1}, S_{\mathrm{BET}}=1150 \mathrm{~m}^{2} \mathrm{~g}^{-1}\right){ }^{82}$ After the initial exposure to $\mathrm{H}_{2} \mathrm{~S}$, the sample was reactivated and used for a second $\mathrm{H}_{2} \mathrm{~S}$ adsorption cycle. Interestingly, the capacity initially observed was lost $\left(0.2 \mathrm{mmol} \mathrm{g}^{-1}\right.$, Figure 6) despite an apparent preservation of the framework, as observed by PXRD (Figure S29). To further investigate the seemingly lost porosity, a $\mathrm{N}_{2}$ sorption experiment at $77 \mathrm{~K}$ was performed, showing a specific surface area of $15 \mathrm{~m}^{2} \mathrm{~g}^{-1}$. As the framework remains intact, we hypothesize that $\mathrm{H}_{2} \mathrm{~S}$ is captured by SU-101 via a chemisorption process, leading to the formation of polysulfides. To test this hypothesis, Raman spectra of SU-101 were acquired before and after $\mathrm{H}_{2} \mathrm{~S}$ adsorption (Figure S30). After exposure to $\mathrm{H}_{2} \mathrm{~S}$ two additional peaks appear, one at 243 $\mathrm{cm}^{-1}$ corresponding to different $\mathrm{S}_{n}{ }^{2-}$ species ${ }^{83,84}$ and another at $445 \mathrm{~cm}^{-1}$ corresponding to $\mathrm{S}_{4}{ }^{2-}{ }^{n} \cdot 83,85,86$ These characteristic peaks support the hypothesized chemisorption of $\mathrm{H}_{2} \mathrm{~S}$ within SU-101, resulting in the formation of polysulfides. We have recently published a similar phenomenon for MFM-300(Sc), ${ }^{81}$ where the MOF can oxidize $\mathrm{H}_{2} \mathrm{~S}$, forming low order polysulfides $(n=2)$ species. Presumably, the electrochemical potential of SU-101 should be similar to the one for MFM$300(\mathrm{Sc})(2.29 \mathrm{~V}),{ }^{81}$ considering that $\mathrm{S}_{4}{ }^{2-}$ species were also found for MFM-300(Sc). The mechanism of polysulfide formation from $\mathrm{H}_{2} \mathrm{~S}$ includes the adsorption of $\mathrm{H}_{2} \mathrm{~S}$, dissociation, oxidation, and recombination of sulfur species. ${ }^{81,87}$ Diffuse-reflectance Fourier-transform infrared spectroscopy experiments (Figure S31) were conducted on SU-101 before and after $\mathrm{H}_{2} \mathrm{~S}$ adsorption to explore the possible perturbation of the band characteristic of the phenolate stretching vibration in the ellagate anion $\left(3408 \mathrm{~cm}^{-1}\right)$. This band was shifted to a lower wavenumber $\left(3100 \mathrm{~cm}^{-1}\right)$ after $\mathrm{H}_{2} \mathrm{~S}$ sorption, suggesting a relatively strong interaction between the phenolate group of SU-101 and the polysulfides, as previously reported for other MOFs. ${ }^{81,82}$ This polysulfide formation, paired with the high stability of the material, could pave the way toward applications such as the construction of a MOF-based lithium/sulfur battery.

\section{CONCLUSIONS}

As the first MOF synthesized from ellagic acid, SU-101 exemplifies the use of a renewable phenol-functionalized and plant-based linker to construct a highly chemically stable and biocompatible MOF under scalable, green, and ambient synthesis conditions. $\mathrm{Bi}^{3+}$ was the first cation we combined with ellagic acid in an attempt to develop a new MOF, resulting in SU-101. We therefore expect that a plethora of new crystal structures, including MOFs and coordination polymers, can be synthesized from ellagic acid as well as other previously unexplored phenolic phytochemicals. As the synthesis of SU101 was carried out at room temperature and atmospheric pressure, further scale-up is expected to be feasible. Combining sustainable green solvents, such as water, with renewable and inexpensive linkers as well as biocompatible inorganic species in the design and synthesis of new framework materials paves the way for further development of MOFs as green materials for environmental and health applications, including, but certainly not limited to, gas capture and drug delivery.

\section{ASSOCIATED CONTENT}

\section{SI Supporting Information}

The Supporting Information is available free of charge at https://pubs.acs.org/doi/10.1021/jacs.0c07525.

SEM images, TEM images, crystallographic tables, PXRD patterns, VT-PXRD patterns, gas adsorption results, thermogravimetric analysis results, colloidal stability studies, cytotoxicity studies, Raman spectra, and FT-IR spectra (PDF)

CCDC 2003313, crystallographic data (CIF) 


\section{Accession Codes}

CCDC 2003313 contains the supplementary crystallographic data for this paper. These data can be obtained free of charge via www.ccdc.cam.ac.uk/data_request/cif, or by emailing data_request@ccdc.cam.ac.uk, or by contacting The Cambridge Crystallographic Data Centre, 12 Union Road, Cambridge CB2 1EZ, U.K.; fax: + 441223336033.

\section{AUTHOR INFORMATION}

\section{Corresponding Authors}

A. Ken Inge - Department of Materials and Environmental Chemistry, Stockholm University, Stockholm 106 91, Sweden; • orcid.org/0000-0001-9118-1342; Email: andrew.inge@ mmk.su.se

Patricia Horcajada - Advanced Porous Materials Unit, IMDEA Energy, 28935 Móstoles, Madrid, Spain; 이이.org/00000002-6544-5911; Email: patricia.horcajada@imdea.org

Ilich A. Ibarra - Laboratorio de Fisicoquimica y Reactividad de Superficies (LaFReS), Instituto de Investigaciones en Materiales, Universidad Nacional Autónoma de Mexico, 04510 Ciudad de

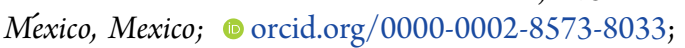
Email: argel@unam.mx

\section{Authors}

Erik Svensson Grape - Department of Materials and Environmental Chemistry, Stockholm University, Stockholm 106 91, Sweden; 이이이.org/0000-0002-8956-5897

J. Gabriel Flores - Laboratorio de Fisicoquimica y Reactividad de Superficies (LaFReS), Instituto de Investigaciones en Materiales, Universidad Nacional Autónoma de México, 04510 Ciudad de México, Mexico; Departamento de Ciencias Básicas, Universidad Autonoma Metropolitana-Azcapotzalco, 02120 Ciudad de México, Mexico

Tania Hidalgo - Advanced Porous Materials Unit, IMDEA Energy, 28935 Móstoles, Madrid, Spain; 이이.org/00000002-3498-9967

Eva Martínez-Ahumada - Laboratorio de Fisicoquímica y Reactividad de Superficies (LaFReS), Instituto de Investigaciones en Materiales, Universidad Nacional Autonoma de Mexico, 04510 Ciudad de México, Mexico

Aída Gutiérrez-Alejandre - UNICAT, Departamento de Ingenieria Quimica, Facultad de Quimica, Universidad Nacional Autónoma de México, 04510 Ciudad de México, Mexico

Audrey Hautier - Départment Sciences et Génie Des Materiaux, INSA, Lyon 69621, France

Daryl R. Williams - Surfaces and Particle Engineering Laboratory (SPEL), Department of Chemical Engineering, Imperial College London, London SW7 2AZ, United Kingdom; (1) orcid.org/0000-0001-5626-5903

Michael O'Keeffe - School of Molecular Sciences, Arizona State University, Tempe, Arizona 85287, United States

Lars Öhrström - Chemistry and Biochemistry, Department of Chemistry and Chemical Engineering, Chalmers University of Technology, SE-41296 Gothenburg, Sweden; ㅈorcid.org/ 0000-0002-6420-2141

Tom Willhammar - Department of Materials and Environmental Chemistry, Stockholm University, Stockholm 106 91, Sweden; (1) orcid.org/0000-0001-6120-1218

Complete contact information is available at: https://pubs.acs.org/10.1021/jacs.0c07525

\section{Notes}

The authors declare no competing financial interest.

\section{ACKNOWLEDGMENTS}

The authors thank Dr. A. Tejeda-Cruz (powder X-ray; IIMUNAM), PAPIIT UNAM (IN202820), México for financial support. We thank U. Winnberg (ITAM) for scientific discussions and G. Ibarra-Winnberg for scientific encouragement. Use of the Advanced Photon Source at Argonne National Laboratory was supported by the U.S. Department of Energy, Office of Science, Office of Basic Energy Sciences, under Contract No. DE-AC02-06CH11357. E.S.G. and A.K.I. acknowledges support from the Swedish Foundation for Strategic Research (SSF). A.K.I. also acknowledges support from the Knut and Alice Wallenberg Foundation (KAW 2016.0072). This research was partially funded by the Raphuel project (ENE2016-79608-C2-1-R, MINECO-AEI/FEDER, $\mathrm{UE)}$, Ramón Areces Foundation project $\mathrm{H}+\mathrm{MOF}$ and MOFSEIDON project (PID2019-104228RB-I00, MINECOAEI/FEDER, UE). P.H. acknowledges the Spanish Ramón y Cajal Programme (grant agreement No. 2014-16823). T.H. and P.H. are thankful for the financial support of the Talento Mod. 2 fellowship from the Madrid Community (2018-T2/ IND-11407) as well as by IMDEA Energy.

\section{REFERENCES}

(1) Arbenz, A.; Avérous, L. Chemical Modification of Tannins to Elaborate Aromatic Biobased Macromolecular Architectures. Green Chem. 2015, 17 (5), 2626-2646.

(2) Rahim, M. A.; Kristufek, S. L.; Pan, S.; Richardson, J. J.; Caruso, F. Phenolic Building Blocks for the Assembly of Functional Materials. Angew. Chem., Int. Ed. 2019, 58 (7), 1904-1927.

(3) Zhou, H. C.; Long, J. R.; Yaghi, O. M. Introduction to MetalOrganic Frameworks. Chem. Rev. 2012, 112, 673-674.

(4) Kitagawa, S. Future Porous Materials. Acc. Chem. Res. 2017, 50 (3), 514-516.

(5) Nakabayashi, K.; Ohkoshi, S. I. Monometallic Lanthanoid Assembly Showing Ferromagnetism with a Curie Temperature of 11 K. Inorg. Chem. 2009, 48 (18), 8647-8649.

(6) Abrahams, B. F.; Grannas, M. J.; Hudson, T. A.; Hughes, S. A.; Pranoto, N. H.; Robson, R. Synthesis, Structure and Host-Guest Properties of $\left.\left(\mathrm{Et}_{4} \mathrm{~N}\right)_{2}[\text { SnivCaii(Chloranilate })_{4}\right]$, a New Type of Robust Microporous Coordination Polymer with a 2D Square Grid Structure. Dalt. Trans. 2011, 40 (45), 12242-12247.

(7) Jeon, I. R.; Negru, B.; Van Duyne, R. P.; Harris, T. D. A 2D Semiquinone Radical-Containing Microporous Magnet with SolventInduced Switching from $\mathrm{T}_{\mathrm{c}}=26$ to $80 \mathrm{~K}$. J. Am. Chem. Soc. 2015, 137 (50), 15699-15702.

(8) Halis, S.; Inge, A. K.; Dehning, N.; Weyrich, T.; Reinsch, H.; Stock, N. Dihydroxybenzoquinone as Linker for the Synthesis of Permanently Porous Aluminum Metal-Organic Frameworks. Inorg. Chem. 2016, 55 (15), 7425-7431.

(9) Hmadeh, M.; Lu, Z.; Liu, Z.; Gándara, F.; Furukawa, H.; Wan, S.; Augustyn, V.; Chang, R.; Liao, L.; Zhou, F.; Perre, E.; Ozolins, V.; Suenaga, K.; Duan, X.; Dunn, B.; Yamamto, Y.; Terasaki, O.; Yaghi, O. M. New Porous Crystals of Extended Metal-Catecholates. Chem. Mater. 2012, 24 (18), 3511-3513.

(10) Nguyen, N. T. T.; Furukawa, H.; Gándara, F.; Trickett, C. A.; Jeong, H. M.; Cordova, K. E.; Yaghi, O. M. Three-Dimensional MetalCatecholate Frameworks and Their Ultrahigh Proton Conductivity. J. Am. Chem. Soc. 2015, 137 (49), 15394-15397.

(11) Leubner, S.; Bengtsson, V. E. G.; Inge, A. K.; Wahiduzzaman, M.; Steinke, F.; Jaworski, A.; Xu, H.; Halis, S.; Rönfeldt, P.; Reinsch, H.; Maurin, G.; Zou, X.; Stock, N. Hexahydroxytriphenylene for the Synthesis of Group 13 MOFs - a New Inorganic Building Unit in a $\beta$ -Cristobalite Type Structure. Dalt. Trans. 2020, 49 (10), 3088-3092. 
(12) Mouchaham, G.; Cooper, L.; Guillou, N.; Martineau, C.; Elkaïm, E.; Bourrelly, S.; Llewellyn, P. L.; Allain, C.; Clavier, G.; Serre, C.; Devic, T. A Robust Infinite Zirconium Phenolate Building Unit to Enhance the Chemical Stability of Zr MOFs. Angew. Chem., Int. Ed. 2015, 54 (45), 13297-13301.

(13) Chen, E. X.; Qiu, M.; Zhang, Y. F.; Zhu, Y. S.; Liu, L. Y.; Sun, Y. Y.; Bu, X.; Zhang, J.; Lin, Q. Acid and Base Resistant Zirconium Polyphenolate-Metalloporphyrin Scaffolds for Efficient $\mathrm{CO}_{2}$ Photoreduction. Adv. Mater. 2018, 30 (2), 1704388.

(14) Weber, R.; Bergerhoff, G. Crystal Structure of Iron(III) Oxonium 3,4,5-Trihydroxybenzoate, $\left(\mathrm{C}_{7} \mathrm{H}_{2} \mathrm{O}_{5}\right) \mathrm{Fe}\left(\mathrm{H}_{3} \mathrm{O}\right)$. Zeitschrift fur Krist. - New Cryst. Struct. 1991, 195, 87-88.

(15) Feller, R. K.; Cheetham, A. K. Fe(III), Mn(II), Co(II), and Ni(II) 3,4,5-Trihydroxybenzoate (Gallate) Dihydrates; a New Family of Hybrid Framework Materials. Solid State Sci. 2006, 8 (9), 11211125.

(16) Saines, P. J.; Yeung, H. H. M.; Hester, J. R.; Lennie, A. R.; Cheetham, A. K. Detailed Investigations of Phase Transitions and Magnetic Structure in $\mathrm{Fe}(\mathrm{III}), \mathrm{Mn}(\mathrm{II}), \mathrm{Co}(\mathrm{II})$ and $\mathrm{Ni}(\mathrm{II})$ 3,4,5Trihydroxybenzoate (Gallate) Dihydrates by Neutron and X-Ray Diffraction. Dalt. Trans. 2011, 40 (24), 6401-6410.

(17) Cooper, L.; Hidalgo, T.; Gorman, M.; Lozano-Fernández, T.; Simón-Vázquez, R.; Olivier, C.; Guillou, N.; Serre, C.; Martineau, C.; Taulelle, F.; Damasceno-Borges, D.; Maurin, G.; González-Fernández, Á.; Horcajada, P.; Devic, T. A Biocompatible Porous Mg-Gallate Metal-Organic Framework as an Antioxidant Carrier. Chem. Commun. 2015, 51 (27), 5848-5851.

(18) Hidalgo, T.; Cooper, L.; Gorman, M.; Lozano-Fernández, T.; Simón-Vázquez, R.; Mouchaham, G.; Marrot, J.; Guillou, N.; Serre, C.; Fertey, P.; González-Fernández, Á.; Devic, T.; Horcajada, P. Crystal Structure Dependent in Vitro Antioxidant Activity of Biocompatible Calcium Gallate MOFs. J. Mater. Chem. B 2017, 5 (15), 2813-2822.

(19) Bao, Z.; Wang, J.; Zhang, Z.; Xing, H.; Yang, Q.; Yang, Y.; Wu, H.; Krishna, R.; Zhou, W.; Chen, B.; Ren, Q. Molecular Sieving of Ethane from Ethylene through the Molecular Cross-Section Size Differentiation in Gallate-Based Metal-Organic Frameworks. Angew. Chem., Int. Ed. 2018, 57 (49), 16020-16025.

(20) Mandal, A.; Grupp, A.; Schwederski, B.; Kaim, W.; Lahiri, G. K. Noninnocently Behaving Bridging Anions of the Widely Distributed Antioxidant Ellagic Acid in Diruthenium Complexes. Inorg. Chem. 2015, 54 (20), 10049-10057.

(21) Zhao, G.; Wu, H.; Feng, R.; Wang, D.; Xu, P.; Jiang, P.; Yang, K.; Wang, H.; Guo, Z.; Chen, Q. Novel Metal Polyphenol Framework for MR Imaging-Guided Photothermal Therapy. ACS Appl. Mater. Interfaces 2018, 10 (4), 3295-3304.

(22) Yang, S. J.; Antonietti, M.; Fechler, N. Self-Assembly of Metal Phenolic Mesocrystals and Morphosynthetic Transformation toward Hierarchically Porous Carbons. J. Am. Chem. Soc. 2015, 137 (25), $8269-8273$.

(23) Clifford, M. N.; Scalbert, A. Ellagitannins - Nature, Occurrence and Dietary Burden. J. Sci. Food Agric. 2000, 80, 1118-1125.

(24) Määtä-Riihinen, K. R.; Kamal-Eldin, A.; Törrönen, A. R. Identification and Quantification of Phenolic Compounds in Berries of Fragaria and Rubus Species (Family Rosaceae). J. Agric. Food Chem. 2004, 52, 6178-6187.

(25) Viriot, C.; Scalbert, A.; Lapierre, C.; Moutounet, M. Ellagitannins and Lignins in Aging of Spirits in Oak Barrels. J. Agric. Food Chem. 1993, 41 (11), 1872-1879.

(26) Huang, D. Dietary Antioxidants and Health Promotion. Antioxidants 2018, 7 (1), 9.

(27) Liu, Z.; Ren, Z.; Zhang, J.; Chuang, C. C.; Kandaswamy, E.; Zhou, T.; Zuo, L. Role of ROS and Nutritional Antioxidants in Human Diseases. Front. Physiol. 2018, 9 (MAY), No. 477.

(28) Landete, J. M. Ellagitannins, Ellagic Acid and Their Derived Metabolites: A Review about Source, Metabolism, Functions and Health. Food Res. Int. 2011, 44 (5), 1150-1160.

(29) Zhong, C.; Qiu, S.; Li, J.; Shen, J.; Zu, Y.; Shi, J.; Sui, G. Ellagic Acid Synergistically Potentiates Inhibitory Activities of Chemo- therapeutic Agents to Human Hepatocellular Carcinoma. Phytomedicine 2019, 59, 152921.

(30) Ceci, C.; Lacal, P. M.; Tentori, L.; De Martino, M. G.; Miano, R.; Graziani, G. Experimental Evidence of the Antitumor, Antimetastatic and Antiangiogenic Activity of Ellagic Acid. Nutrients 2018, 10 (11), 1756.

(31) Sivakova, S.; Rowan, S. J. Nucleobases as Supramolecular Motifs. Chem. Soc. Rev. 2005, 34 (1), 9-21.

(32) Imaz, I.; Rubio-Martínez, M.; An, J.; Solé-Font, I.; Rosi, N. L.; Maspoch, D. Metal-Biomolecule Frameworks (MBioFs). Chem. Commun. 2011, 47, 7287-7302.

(33) McKinlay, A. C.; Morris, R. E.; Horcajada, P.; Férey, G.; Gref, R.; Couvreur, P.; Serre, C. BioMOFs: Metal-Organic Frameworks for Biological and Medical Applications. Angew. Chem., Int. Ed. 2010, 49 (36), 6260-6266.

(34) Horcajada, P.; Gref, R.; Baati, T.; Allan, P. K.; Maurin, G.; Couvreur, P.; Férey, G.; Morris, R. E.; Serre, C. Metal-Organic Frameworks in Biomedicine. Chem. Rev. 2012, 112 (2), 1232-1268.

(35) Rojas, S.; Devic, T.; Horcajada, P. Metal Organic Frameworks Based on Bioactive Components. J. Mater. Chem. B 2017, 5 (14), 2560-2573.

(36) Cai, H.; Huang, Y. L.; Li, D. Biological Metal-Organic Frameworks: Structures, Host-Guest Chemistry and Bio-Applications. Coord. Chem. Rev. 2019, 378, 207-221.

(37) Chalati, T.; Horcajada, P.; Gref, R.; Couvreur, P.; Serre, C. Optimisation of the Synthesis of MOF Nanoparticles Made of Flexible Porous Iron Fumarate MIL-88A. J. Mater. Chem. 2011, 21 (7), 2220-2227.

(38) Gaab, M.; Trukhan, N.; Maurer, S.; Gummaraju, R.; Müller, U. The Progression of Al-Based Metal-Organic Frameworks - From Academic Research to Industrial Production and Applications. Microporous Mesoporous Mater. 2012, 157, 131-136.

(39) Wißmann, G.; Schaate, A.; Lilienthal, S.; Bremer, I.; Schneider, A. M.; Behrens, P. Modulated Synthesis of Zr-Fumarate MOF. Microporous Mesoporous Mater. 2012, 152, 64-70.

(40) Inge, A. K.; Köppen, M.; Su, J.; Feyand, M.; Xu, H.; Zou, X.; O'Keeffe, M.; Stock, N. Unprecedented Topological Complexity in a Metal-Organic Framework Constructed from Simple Building Units. J. Am. Chem. Soc. 2016, 138 (6), 1970-1976.

(41) Grape, E. S.; Xu, H.; Cheung, O.; Calmels, M.; Zhao, J.; Dejoie, C.; Proserpio, D. M.; Zou, X.; Inge, A. K. Breathing Metal-Organic Framework Based on Flexible Inorganic Building Units. Cryst. Growth Des. 2020, 20 (1), 320-329.

(42) Sano, Y.; Satoh, H.; Chiba, M.; Okamoto, M.; Serizawa, K.; Nakashima, H.; Omae, K. Oral Toxicity of Bismuth in Rat: Single and 28-Day Repeated Administration Studies. J. Occup. Health 2005, 47 (4), 293-298.

(43) Yang, N.; Sun, H. Biocoordination Chemistry of Bismuth: Recent Advances. Coord. Chem. Rev. 2007, 251 (17-20), 2354-2366.

(44) Wang, Y.; Takki, S.; Cheung, O.; Xu, H.; Wan, W.; Öhrström, L.; Inge, A. K. Elucidation of the Elusive Structure and Formula of the Active Pharmaceutical Ingredient Bismuth Subgallate by Continuous Rotation Electron Diffraction. Chem. Commun. 2017, 53 (52), 70187021.

(45) Feyand, M.; Mugnaioli, E.; Vermoortele, F.; Bueken, B.; Dieterich, J. M.; Reimer, T.; Kolb, U.; De Vos, D.; Stock, N. Automated Diffraction Tomography for the Structure Elucidation of Twinned, Sub-Micrometer Crystals of a Highly Porous, Catalytically Active Bismuth Metal-Organic Framework. Angew. Chem., Int. Ed. 2012, 51 (41), 10373-10376.

(46) Savage, M.; Yang, S.; Suyetin, M.; Bichoutskaia, E.; Lewis, W.; Blake, A. J.; Barnett, S. A.; Schröder, M. A Novel Bismuth-Based Metal-Organic Framework for High Volumetric Methane and Carbon Dioxide Adsorption. Chem. - Eur. J. 2014, 20 (26), 8024-8029.

(47) Köppen, M.; Meyer, V.; Ångström, J.; Inge, A. K.; Stock, N. Solvent-Dependent Formation of Three New Bi-Metal-Organic Frameworks Using a Tetracarboxylic Acid. Cryst. Growth Des. 2018, 18 (7), 4060-4067. 
(48) Robison, L.; Zhang, L.; Drout, R. J.; Li, P.; Haney, C. R.; Brikha, A.; Noh, H.; Mehdi, B. L.; Browning, N. D.; Dravid, V. P.; Cui, Q.; Islamoglu, T.; Farha, O. K. A Bismuth Metal-Organic Framework as a Contrast Agent for X-Ray Computed Tomography. ACS Appl. Bio Mater. 2019, 2, 1197-1203.

(49) Amombo Noa, F. M.; Svensson Grape, E.; Brülls, S. M.; Cheung, O.; Malmberg, P.; Inge, A. K.; McKenzie, C. J.; Mårtensson, J.; Öhrström, L. Metal-Organic Frameworks with Hexakis(4Carboxyphenyl)Benzene: Extensions to Reticular Chemistry and Introducing Foldable Nets. J. Am. Chem. Soc. 2020, 142 (20), 94719481.

(50) Amoatey, P.; Omidvarborna, H.; Baawain, M. S.; Al-Mamun, A. Emissions and Exposure Assessments of $\mathrm{SO}_{\mathrm{X}}, \mathrm{NO}_{\mathrm{X}}, \mathrm{PM}_{10 / 2.5}$ and Trace Metals from Oil Industries: A Review Study (2000-2018). Process Saf. Environ. Prot. 2019, 123 (2), 215-228.

(51) Beauchamp, R. O.; Bus, J. S.; Popp, J. A.; Boreiko, C. J.; Andjelkovich, D. A.; Leber, P. A Critical Review of the Literature on Hydrogen Sulfide Toxicity. Crit. Rev. Toxicol. 1984, 13 (1), 25-97.

(52) Kahn, J. H.; Nickol, G. B.; Conner, H. A. Analysis of Vinegar by Gas-Liquid Chromatography. J. Agric. Food Chem. 1966, 14 (5), 460465.

(53) Reinsch, H.; Waitschat, S.; Chavan, S. M.; Lillerud, K. P.; Stock, N. A Facile "Green" Route for Scalable Batch Production and Continuous Synthesis of Zirconium MOFs. Eur. J. Inorg. Chem. 2016, 2016 (27), 4490-4498.

(54) O'Keeffe, M.; Yaghi, O. M. Deconstructing the Crystal Structures of Metal-Organic Frameworks and Related Materials into Their Underlying Nets. Chem. Rev. 2012, 112, 675-702.

(55) Healy, C.; Patil, K. M.; Wilson, B. H.; Hermanspahn, L.; Harvey-Reid, N. C.; Howard, B. I.; Kleinjan, C.; Kolien, J.; Payet, F.; Telfer, S. G.; Kruger, P. E.; Bennett, T. D. The Thermal Stability of Metal-Organic Frameworks. Coord. Chem. Rev. 2020, 419, 213388.

(56) Sabouni, R.; Kazemian, H.; Rohani, S. Carbon Dioxide Capturing Technologies: A Review Focusing on Metal Organic Framework Materials (MOFs). Environ. Sci. Pollut. Res. 2014, 21 (8), 5427-5449.

(57) Lamagni, P.; Miola, M.; Catalano, J.; Hvid, M. S.; Mamakhel, M. A. H.; Christensen, M.; Madsen, M. R.; Jeppesen, H. S.; Hu, X. M.; Daasbjerg, K.; Skrydstrup, T.; Lock, N. Restructuring MetalOrganic Frameworks to Nanoscale Bismuth Electrocatalysts for Highly Active and Selective $\mathrm{CO}_{2}$ Reduction to Formate. Adv. Funct. Mater. 2020, 30 (16), 1910408.

(58) Ding, M.; Cai, X.; Jiang, H. L. Improving MOF Stability: Approaches and Applications. Chem. Sci. 2019, 10 (44), 1020910230 .

(59) Nel, A. E.; Mädler, L.; Velegol, D.; Xia, T.; Hoek, E. M. V.; Somasundaran, P.; Klaessig, F.; Castranova, V.; Thompson, M. Understanding Biophysicochemical Interactions at the Nano-Bio Interface. Nat. Mater. 2009, 8 (7), 543-557.

(60) Mitragotri, S.; Burke, P. A.; Langer, R. Overcoming the Challenges in Administering Biopharmaceuticals: Formulation and Delivery Strategies. Nat. Rev. Drug Discovery 2014, 13 (9), 655-672.

(61) Fattal, E.; Tsapis, N. Nanomedicine Technology: Current Achievements and New Trends. Clin. Transl. Imaging 2014, 2 (1), 77-87.

(62) Giménez-Marqués, M.; Hidalgo, T.; Serre, C.; Horcajada, P. Nanostructured Metal-Organic Frameworks and Their Bio-Related Applications. Coord. Chem. Rev. 2016, 307, 342-360.

(63) Baati, T.; Njim, L.; Neffati, F.; Kerkeni, A.; Bouttemi, M.; Gref, R.; Najjar, M. F.; Zakhama, A.; Couvreur, P.; Serre, C.; Horcajada, P. In Depth Analysis of the in Vivo Toxicity of Nanoparticles of Porous Iron(III) Metal-Organic Frameworks. Chem. Sci. 2013, 4 (4), 15971607.

(64) Bellido, E.; Guillevic, M.; Hidalgo, T.; Santander-Ortega, M. J.; Serre, C.; Horcajada, P. Understanding the Colloidal Stability of the Mesoporous MIL-100(Fe) Nanoparticles in Physiological Media. Langmuir 2014, 30 (20), 5911-5920.
(65) Matooane, M.; Diab, R. Health Risk Assessment for Sulfur Dioxide Pollution in South Durban, South Africa. Arch. Environ. Health 2003, 58 (12), 763-770.

(66) Schwartz, J.; Dockery, D. W. Increased Mortality in Philadelphia Associated with Daily Air Pollution Concentrations. Am. Rev. Respir. Dis. 1992, 145 (3), 600-604.

(67) Moore, P. K.; Whiteman, M. Handbook of Experimental Pharmacology; Barret, J. E., Ed.; Springer Internation Publishing, 2015.

(68) Córdoba, P. Status of Flue Gas Desulphurisation (FGD) Systems from Coal-Fired Power Plants: Overview of the PhysicChemical Control Processes of Wet Limestone FGDs. Fuel 2015, 144, 274-286.

(69) Savage, M.; Cheng, Y.; Easun, T. L.; Eyley, J. E.; Argent, S. P.; Warren, M. R.; Lewis, W.; Murray, C.; Tang, C. C.; Frogley, M. D.; Cinque, G.; Sun, J.; Rudić, S.; Murden, R. T.; Benham, M. J.; Fitch, A. N.; Blake, A. J.; Ramirez-Cuesta, A. J.; Yang, S.; Schröder, M. Selective Adsorption of Sulfur Dioxide in a Robust Metal-Organic Framework Material. Adv. Mater. 2016, 28 (39), 8705-8711.

(70) Smith, G. L.; Eyley, J. E.; Han, X.; Zhang, X.; Li, J.; Jacques, N. M.; Godfrey, H. G. W.; Argent, S. P.; McCormick McPherson, L. J.; Teat, S. J.; Cheng, Y.; Frogley, M. D.; Cinque, G.; Day, S. J.; Tang, C. C.; Easun, T. L.; Rudić, S.; Ramirez-Cuesta, A. J.; Yang, S.; Schröder, M. Reversible Coordinative Binding and Separation of Sulfur Dioxide in a Robust Metal-Organic Framework with Open Copper Sites. Nat. Mater. 2019, 18 (12), 1358-1365.

(71) Zárate, J. A.; Sánchez-González, E.; Williams, D. R.; GonzálezZamora, E.; Martis, V.; Martínez, A.; Balmaseda, J.; Maurin, G.; Ibarra, I. A. High and Energy-Efficient Reversible $\mathrm{SO}_{2}$ Uptake by a Robust Sc(III)-Based MOF. J. Mater. Chem. A 2019, 7 (26), 1558015584 .

(72) Martínez-Ahumada, E.; Díaz-Ramírez, M. L.; Lara-García, H. A.; Williams, D. R.; Martis, V.; Jancik, V.; Lima, E.; Ibarra, I. A. High and Reversible $\mathrm{SO}_{2}$ Capture by a Chemically Stable $\mathrm{Cr}(\mathrm{III})$ - Based MOF. J. Mater. Chem. A 2020, 8, 11515-11520.

(73) Adib, F.; Bagreev, A.; Bandosz, T. J. Adsorption/Oxidation of Hydrogen Sulfide on Nitrogen-Containing Activated Carbons. Langmuir 2000, 16 (4), 1980-1986.

(74) Hamon, L.; Serre, C.; Devic, T.; Loiseau, T.; Millange, F.; Ferey, G.; De Weireld, G. Comparative Study of Hydrogen Sulfide Adsorption in the MIL-53(Al, Cr, Fe), MIL-47(V), MIL-100(Cr), and MIL-101(Cr) Metal-Organic Frameworks at Room Temperature. J. Am. Chem. Soc. 2009, 131 (25), 8775-8777.

(75) Petit, C.; Mendoza, B.; Bandosz, T. J. Hydrogen Sulfide Adsorption on MOFs and MOF/Graphite Oxide Composites. ChemPhysChem 2010, 11 (17), 3678-3684.

(76) Yu, K.; Kiesling, K.; Schmidt, J. R. Trace Flue Gas Contaminants Poison Coordinatively Unsaturated Metal-Organic Frameworks: Implications for $\mathrm{CO}_{2}$ Adsorption and Separation. J. Phys. Chem. C 2012, 116 (38), 20480-20488.

(77) Yang, S.; Liu, L.; Sun, J.; Thomas, K. M.; Davies, A. J.; George, M. W.; Blake, A. J.; Hill, A. H.; Fitch, A. N.; Tang, C. C.; Schröder, M. Irreversible Network Transformation in a Dynamic Porous Host Catalyzed by Sulfur Dioxide. J. Am. Chem. Soc. 2013, 135 (13), 49544957.

(78) Carter, J. H.; Han, X.; Moreau, F. Y.; Da Silva, I.; Nevin, A.; Godfrey, H. G. W.; Tang, C. C.; Yang, S.; Schröder, M. Exceptional Adsorption and Binding of Sulfur Dioxide in a Robust ZirconiumBased Metal-Organic Framework. J. Am. Chem. Soc. 2018, 140 (46), 15564-15567.

(79) Tan, K.; Zuluaga, S.; Wang, H.; Canepa, P.; Soliman, K.; Cure, J.; Li, J.; Thonhauser, T.; Chabal, Y. J. Interaction of Acid Gases $\mathrm{SO}_{2}$ and $\mathrm{NO}_{2}$ with Coordinatively Unsaturated Metal Organic Frameworks: M-MOF-74 (M = Zn, Mg, Ni, Co). Chem. Mater. 2017, 29 (10), 4227-4235.

(80) Allan, P. K.; Wheatley, P. S.; Aldous, D.; Mohideen, M. I.; Tang, C.; Hriljac, J. A.; Megson, I. L.; Chapman, K. W.; De Weireld, G.; Vaesen, S.; Morris, R. E. Metal-Organic Frameworks for the Storage and Delivery of Biologically Active Hydrogen Sulfide. Dalt. Trans. 2012, 41 (14), 4060-4066. 
(81) Flores, J. G.; Zarate-Colin, J. A.; Sanchez-Gonzalez, E.; Valenzuela, J. R.; Gutierrez-Alejandre, A.; Ramirez, J.; Jancik, V.; Aguilar-Pliego, J.; Zorrilla, M. C.; Lara-Garcia, H. A.; et al. Partially Reversible $\mathrm{H}_{2} \mathrm{~S}$ Adsorption by MFM-300(Sc): Formation of Polysulfides. ACS Appl. Mater. Interfaces 2020, 12 (16), 1888518892.

(82) Zarate, J. A.; Sanchez-Gonzalez, E.; Jurado-Vazquez, T.; Gutierrez-Alejandre, A.; Gonzalez-Zamora, E.; Castillo, I.; Maurin, G.; Ibarra, I. A. Outstanding Reversible $\mathrm{H}_{2} \mathrm{~S}$ Capture by an $\mathrm{Al}(\mathrm{III})$ Based MOF. Chem. Commun. 2019, 55 (21), 3049-3052.

(83) Chivers, T.; Lau, C. Raman Spectroscopic Identification of the $\mathrm{S}_{4} \mathrm{~N}^{-}$and $\mathrm{S}^{3-}$ Ions in Blue Solutions of Sulfur in Liquid Ammonia. Inorg. Chem. 1982, 21 (1), 453-455.

(84) El Jaroudi, O.; Picquenard, E.; Demortier, A.; Lelieur, J.-P.; Corset, J. Polysulfide Anions. 1. Structure and Vibrational Spectra of the $\mathrm{S}_{2}{ }^{2-}$ and $\mathrm{S}_{3}{ }^{2-}$ Anions. Influence of the Cations on Bond Length and Angle. Inorg. Chem. 1999, 38, 2394-2401.

(85) El Jaroudi, O.; Picquenard, E.; Demortier, A.; Lelieur, J. P.; Corset, J. Polysulfide Anions II: Structure and Vibrational Spectra of the $\mathrm{S}_{4}{ }^{2-}$ and $\mathrm{S}_{5}{ }^{2-}$ Anions. Influence of the Cations on Bond Length, Valence, and Torsion Angle. Inorg. Chem. 2000, 39 (12), 2593-2603.

(86) Wu, H. L.; Huff, L. A.; Gewirth, A. A. In Situ Raman Spectroscopy of Sulfur Speciation in Lithium-Sulfur Batteries. ACS Appl. Mater. Interfaces 2015, 7 (3), 1709-1719.

(87) Startsev, A. N. The Reaction Mechanisms of $\mathrm{H}_{2} \mathrm{~S}$ Decomposition into Hydrogen and Sulfur: Application of Classical and Biological Thermodynamics. J. Thermodyn. Catal. 2017, 08 (02), $2-10$. 